\title{
ATIVIDADES E MOTIVAÇÃO PARA A ADESÃO EM GRUPOS DE CONVIVENNCIA PARA IDOSOS
}

\author{
Aline Oliveira Dias Moura ${ }^{1}$ \\ Luciana Karine de Souza²
}

resumo

O presente trabalho tem por objetivo comparar participantes, egressos e desinteressados por grupos de convivência (GC) para idosos, especificamente quanto às atividades realizadas no GC e em outros espaços, bem como a motivação associada. Trata-se de um estudo descritivo e comparativo, de abordagem quali-quantitativa, que busca contribuir para a literatura dedicada aos profissionais que atuam em GC para idosos. Ao mesmo tempo em que o GC oferece uma programação mais estruturada e ampla, com atividades físicas, ele restringe a quantidade de contextos de interação ao qual o idoso pode ser exposto. Os idosos desinteressados estão participando de contextos variados na cidade de Belo Horizonte, Minas Gerais, com a possibilidade de exploração de atividades de seu interesse e, portanto, intrinsecamente motivadas. Esse grupo de desinteressados também está exposto a mais interações sociais com potencial

1 Graduada em Educação Física. Mestre em Estudos do Lazer. Tutora na Universidade Federal de Minas Gerais. E-mail: alineo.dias@hotmail.com.

2 Graduada em Psicologia. Doutora em Psicologia. Pós-doutoranda na Universidade Federal do Rio Grande do Sul. E-mail: luciana.karine@ufrgs.br. 
para desenvolvimento saudável, especialmente se buscadas com a intenção de lazer (por descanso, divertimento ou desenvolvimento pessoal ou social).

palavras-chave

Idoso. Atividades de Lazer. Motivação. Grupo.

\section{Introdução}

Grupos de convivência (GC) são espaços que permitem a sociabilidade do grupo populacional com mais de 60 anos. Também podem ser nomeados como centros de vivência, clubes ou grupos da terceira idade/de idosos, dentre outras nomeações (OLIVEIRA; CABRAL, 2004). Os GC facilitam a sociabilização e a manutenção de direitos e papéis sociais; auxiliam o idoso a lidar com perdas; mantêm e adaptam pelo maior tempo possível a independência física, mental e social; estimulam o desenvolvimento da criatividade; reconstroem padrões de vida e atividades; e avaliam o desempenho adaptativo do idoso como indicador de saúde (FERRARI, 2002).

A literatura nacional sobre grupos de convivência para idosos é vasta, embora a maioria dos trabalhos descreva o que um grupo específico proporciona aos participantes e de que modo as experiências impactam seu bem-estar. Comumente, são pesquisas ou relatos de experiências de projetos de extensão com delineamento exploratório e descritivo, de abordagem predominantemente qualitativa, com uso de observação-participante e entrevistas, registros em cadernos de campo (SILVEIRA et al., 2010).

O presente trabalho tem por objetivo apresentar a segunda etapa da pesquisa realizada sobre comparações entre participantes, egressos e desinteressados por grupos de convivência para idosos. Os dados relatados descrevem as atividades realizadas por participantes de GC e por egressos de GC nesse tipo de grupo, bem como as atividades realizadas em outros espaços por desinteressados por GC. A motivação associada às atividades também está relatada e analisada nesta oportunidade. Trata-se, por fim, de um estudo descritivo, mas também comparativo, de abordagem quali-quantitativa e que busca contribuir para a literatura, em especial, para os profissionais que atuam em GC para idosos.

A primeira etapa da pesquisa teve como resultado a identificação das razões que levam os idosos a procurarem um GC, permanecerem nele por 
muito tempo, desistirem do GC e também os motivos para nunca se interessarem por GC. As razões mais citadas para a procura foram as relacionadas com questões de saúde e incentivo por parte de familiares. As razões para a desistência da participação no GC envolveram relações interpessoais (mudou o professor, orientador do GC) e diferenças entre os GC, tanto com respeito à programação das atividades como a acessibilidade ao local. Os desinteressados por GC alegaram como justificativas a grande ocupação do tempo cotidiano com atividades de variadas naturezas. Essas atividades também serão conhecidas no presente trabalho.

Debert (1999) muito bem já argumentou sobre o paradigma concorrente ao da velhice improdutiva, qual seja o da celebração do envelhecimento, que conduz a uma ideia de um "superidoso". Obrigatoriamente, esse novo idoso deve mudar seu modo de agir, de falar, de vestir, deve buscar novidades, muito lazer, exercícios mais modernos, bailes, relacionamentos amorosos, deve usufruir dos novos medicamentos para desempenho sexual e, claro, deve participar de um GC. Todos esses imperativos colaboram para a celebração da terceira idade, em um talvez eufórico e, muitas vezes, irrefletido novo estilo de vida.

Tanto Melo (2003) como Rezende (2008) alertam para a idealização dos GC como os únicos espaços a fornecerem práticas de lazer de excelência para a população idosa. Alves Júnior (2008), de modo mais incisivo, alerta que devem ser evitados os trabalhos que alimentam a ideia de "guetos para idosos", o que poderia estar sendo encorajado nessa fantasiação dos GC.

Um dos desfechos dessa celebração do envelhecimento é a negação do avanço etário e suas perdas. O lazer tem sido uma válvula de escape para lidar com a alta ansiedade decorrente da vivência desadaptada à idade. Não faltam GC que se dedicam a promover o lazer, mas através da idealização da participação nesses espaços, há o exagero da oferta de práticas, viagens, cursos e a receita de que o GC "te dá a-a-asa-as", como bem ilustra a propaganda da bebida energética Redbull. No entanto, vem sendo alertado que tal estratégia tem servido a afastar muitos idosos da prática saudável de lazer, visto que não se identificam com as propostas fantasiosas do que se pode chamar de uma velhice hiperativa (DIAS; SOUZA, 2011). Desta feita, o estudo sobre o lazer na população idosa pode se beneficiar da investigação das motivações para a procura de lazer em GC ou do afastamento destes grupos. Razões como as recém-discutidas podem privar a população maior de 60 anos dos benefícios físicos, psicológicos e sociais que GC podem proporcionar.

Certamente, a participação em GC tem o potencial de gerar bem-estar ao idoso. Muitos buscam esses espaços para fins de saúde (GÁSPARI; SCHWARTZ, 2005; FENALTI; SCHWARTZ, 2003; GOMES; PINTO, 2007; 
PENNA; ESPÍRITO SANTO, 2006), socialização e amizades (FERNANDES et al., 2011; OLIVEIRA; CABRAL; 2004; PEREIRA; PEREIRA; MORELLI, 2006; SOUZA, 2004; SOUZA; GARCIA, 2008), e adquirir conhecimentos (CASTRO, 1998; 2001; 2004; FERNANDES et al., 2011; SOUZA, 2001). O lazer, nos GC, oferece oportunidades para divertimento, descaso e desenvolvimento pessoal e social, como preconizado por Dumazedier (1976) e reforçado por Marcellino (2007). Isso é argumentado na literatura nacional, embora a maioria não utilize os modelos teóricos desenvolvidos no campo dos estudos interdisciplinares do lazer.

Raros são os trabalhos que informam os fatores envolvidos na desistência de idosos da participação em GC. Os poucos relatos mencionam morte na família ou problemas de saúde que inviabilizam, majoritariamente, as atividades que envolvem movimento ou esforço físico. Além disso, nenhum estudo foi localizado acerca das razões que fundamentam o desinteresse de idosos por GC. Foi também por esse motivo que a presente pesquisa foi desenvolvida, cuja segunda etapa é relatada nesta oportunidade. Os primeiros indícios de outras justificativas para a desistência da participação nos GC e para o desinteresse nesse tipo de contexto relacional já vêm sendo discutidos na literatura, ainda que raramente. Em especial, há indícios de tédio, infantilização ou estereotipia nas atividades propostas e dificuldades de locomoção até o local dos grupos (DIAS; SOUZA, 2011).

O objetivo do presente trabalho é descrever e comparar as atividades e as motivações de participantes, egressos e desinteressados por GC para idosos. Para além de se conhecer as motivações da entrada e da permanência em GC, buscamos comparar essas motivações com aquelas advindas de pessoas que saíram desses grupos, com o objetivo de conhecer o motivo da desistência. Além disso, buscamos também abordar idosos em condições e com interesse em potencial nesses grupos, mas que deles nunca participaram, com o intuito de acessar suas impressões sobre os GC. O estudo se justifica pela carência de pesquisas similares e sua relevância está no potencial para contribuições a profissionais que pretendem trabalhar com as vivências de lazer em GC. 
Utilizando-se o critério de conveniência, obteve-se a colaboração de 12 idosos participantes de GC, 12 egressos de GC e 12 idosos que nunca participaram desses grupos. A idade mínima dos sujeitos da pesquisa foi de 60 anos, e a média de idade ao final foi de 70,9 anos. Cada grupo foi composto por seis mulheres e seis homens, sem distinção de nível socioeconômico. Evitou-se convidar idosos que apresentassem alguma patologia ou problema de saúde, bem como algum défice cognitivo (por exemplo, dificuldades de memorização). Com o auxílio da Prefeitura de Belo Horizonte, Minas Gerais, foram localizados os três GC mais antigos ainda em funcionamento para o convite aos idosos e composição do grupo de participantes. Nesses mesmos GC, com a colaboração do coordenador, foram obtidos dados de egressos para que fossem convidados a participar da pesquisa. O grupo de desinteressados por GC também foi formado a partir de indicações de contatos feitos pelos demais idosos.

$\mathrm{O}$ instrumento utilizado na coleta de dados foi um roteiro de entrevista semiestruturado elaborado especialmente para a pesquisa com base na literatura associada. Nesta segunda etapa da pesquisa, foram analisadas as respostas sobre as atividades realizadas atualmente ou previamente no GC (para participantes e egressos) e as atividades de lazer no tempo livre dos desinteressados e motivações para tal adesão. As entrevistas foram realizadas em local adequado e fornecido pela coordenação do GC ou no domicílio do idoso, assim como gravadas em áudio para posterior transcrição e uso na análise de dados. A pesquisa foi aprovada pelo Comitê de Ética em Pesquisa da Universidade Federal de Minas Gerais (COEP-UFMG) (ETIC 190/11).

As transcrições das entrevistas foram analisadas com base nas técnicas sugeridas por Bardin (2009) em seu referencial da análise de conteúdo. Dois avaliadores independentes criaram categorias de respostas com conteúdos semelhantes em sentido, destacados das transcrições como unidades temáticas. Cada pergunta da entrevista gerou seu conjunto de categorias. As categorias dos dois avaliadores foram posteriormente comparadas e discutidas com a presença de um terceiro avaliador para o desempate diante de dúvidas. Ao final, foi contabilizada a quantidade de respostas (frequência) por categoria e por questão. Por essa razão, é possível notar, por vezes, que a frequência de respostas em uma dada categoria excede o total de sujeitos de um dos três grupos estudados. As categorias de maior frequência de respostas, bem como aquelas de conteúdo relevante, foram interpretadas na seção de discussão com base na literatura. 
Serão apresentados os resultados por grupo de sujeitos da pesquisa, ou seja, primeiramente os dados relativos aos participantes, seguidos dos egressos, e finalmente os dados sobre o grupo de desinteressados. Quatro tabelas auxiliam na visualização dos resultados e ilustram os conteúdos que formaram as categorias de respostas.

\subsection{Atividades e motivação dos participantes de GC}

A Tabela 1 apresenta as atividades realizadas pelos idosos participantes de GC nesses grupos. Os exercícios para independência física envolvem as atividades físicas cujo objetivo central é promover e manter a independência física do idoso. Por essa razão, ficou separada a dança, que embora seja também de natureza física, não possui como objetivo central a independência física do indivíduo. A prática de dança ocorre nos contextos das aulas, enquanto os bailes são momentos fora das aulas e organizados para os idosos.

Tabela 1 - Atividades realizadas no grupo de convivência pelos participantes

\begin{tabular}{l|l|c}
\hline \multicolumn{1}{c|}{ Atividade } & \multicolumn{1}{|c}{ Exemplo } & f \\
\hline Exercícios para independência física & Caminhada, ginástica, ioga & 12 \\
\hline Festas/comemorações & Festa junina, Dia das Mães, aniversários & 10 \\
\hline Passeios & - & 8 \\
\hline Dança & Dança, quadrilha & 6 \\
\hline Interações sociais & Conversar, fazer amizade & 4 \\
\hline Baile & Baile, forró & 3 \\
\hline Brincadeiras & - & 3 \\
\hline Bingo & - & 3 \\
\hline Práticas musicais & Coral, tocar para o grupo & 3 \\
\hline Trabalhos manuais & Artesanato, crochê, tricô, bordado & 2 \\
\hline Outras & Rezar, trabalho voluntário & 2 \\
\hline
\end{tabular}

Nota. $f$ = frequência de respostas.

A Tabela 1 mostra que todos os participantes de GC relataram exercícios que objetivam a independência física. Festas, comemorações e passeios foram muito citados. Não constam na tabela as práticas preferidas, pois a maioria não elegeu uma (7 pessoas), afirmando gostar de todas que o GC oferece. Quatro pessoas preferem os exercícios e duas preferem os passeios. 
Com a intenção de verificar a origem da motivação do participante sobre sua frequência ao GC e seu envolvimento nas atividades, buscou-se identificar o que ou quem o incentiva a participar do GC e a engajar-se em suas práticas. A própria força de vontade para frequentar o GC foi citada por 5 pessoas, familiares foram referidos por 4 pessoas, e outras pessoas próximas (colegas, vizinha, coordenadora do programa que abrange o GC) foram mencionadas por 3 participantes. Enquanto isso, o engajamento nas atividades propostas foi mais atribuído a orientadores (professora, coordenadora) (7 respostas), seguidos por 3 respostas sobre vontade própria, e 1 pessoa referiu os colegas como maiores incentivadores para a realização das atividades do GC. Um entrevistado não entendeu a pergunta e forneceu uma resposta não relacionada ao incentivo.

\subsection{Atividades e motivação dos egressos de GC}

A Tabela 2 mostra os resultados sobre as atividades que os egressos desenvolviam no GC. Note-se que são bastante semelhantes em conteúdo às citadas pelo grupo de participantes. A diferença está na categoria passeios/ viagens, com 10 respostas sobre passeios e 1 resposta sobre viagem. Passeios, no caso, são considerados como deslocamentos mais curtos, enquanto viagens envolvem distâncias maiores.

Tabela 2 - Atividades realizadas no grupo de convivência pelos egressos

\begin{tabular}{l|l|c}
\multicolumn{1}{c|}{ Atividade } & \multicolumn{1}{c}{ Exemplo } & f \\
\hline Exercícios para independência física & Caminhada, hidroginástica, ginástica, ioga & 12 \\
\hline Passeios/viagens & - & 11 \\
\hline Festas & - & 5 \\
\hline Baile & Baile, forró & 3 \\
\hline Interação social & Conversar, bater papo & 3 \\
\hline Bingo & Bingo & 3 \\
\hline Dança & Dança, quadrilha & 2 \\
\hline Outras & Coral, pintura, bordado, palestras & 5 \\
\hline
\end{tabular}

Nota. $f$ = frequência de respostas.

Assim como no grupo de participantes, os egressos, em sua totalidade, lembraram dos exercícios como a atividade mais presente no GC. Os passeios/ viagens foram os mais citados na sequência.

Os egressos relataram satisfação quanto às atividades oferecidas no GC (5 respostas), mencionaram os ganhos em termos de relacionamentos interpessoais 
(5 respostas), seja com colegas, seja com os orientadores, e 3 pessoas referiam o avanço em termos de bem-estar físico/mental decorrente da frequência ao GC. Três outras respostas foram fornecidas, mas de conteúdo não relacionado diretamente à questão dos ganhos com a frequência ao GC.

O incentivo para a participação no GC, na visão do egresso, foi baseado de modo equilibrado entre orientadores dos GC (6 respostas) e pessoas próximas ao egresso (amiga, vizinha, colegas) (também 6 respostas). Três pessoas citaram a esposa como responsável pela motivação a participar do GC. Quanto ao empenho nas práticas oferecidas, os egressos calcavam sua motivação, basicamente, nos professores e orientadores (8 respostas). Duas pessoas mencionaram as esposas, 1 citou os colegas, 3 forneceram outras respostas e 1 não respondeu à pergunta.

\subsection{Os espaços frequentados e as atividades dos desinteressados em GC}

Dos 12 desinteressados, ainda que nunca tenham procurado um GC, 8 frequentam espaços e se envolvem em atividades, muitas delas semelhantes às oferecidas aos participantes e às usufruídas pelos egressos. A Tabela 3 mostra esses espaços frequentados pelo grupo de desinteressados. Cabe destacar que alguns idosos frequentam mais de um espaço; por essa razão, o total de respostas é 9 . Quatro pessoas não responderam a essa questão.

Tabela 3 - Espaços frequentados pelos desinteressados por grupos de convivência para idosos.

\begin{tabular}{|c|c|c|c|}
\hline Espaço & Descrição & Motivação para participar & $f$ \\
\hline \multirow{5}{*}{ Grupo estruturado } & Grupo de oração & Encontra paz e divide problemas & \multirow{5}{*}{4} \\
\hline & Clube da maturidade & Se há algo que interessa & \\
\hline & Clube L. & Companheirismo & \\
\hline & Coral e festas da A.-V. & Gosta de sair, onde há música & \\
\hline & Associação de FM. & "Agora tenho tempo." & \\
\hline \multirow{2}{*}{ Trabalho voluntário } & Museu da FEB & Não perguntado & \multirow{2}{*}{2} \\
\hline & Amigas do Lar, no Lar $X$ & "Ajudar funcionários é gratificante." & \\
\hline \multirow{3}{*}{ Outros espaços } & Lugar para dançar & Gosta de sair, onde há música & \multirow{3}{*}{3} \\
\hline & Boteco & "É divertido, conheço pessoas." & \\
\hline & Pilates & Atendimento personalizado & \\
\hline
\end{tabular}

Nota. $\mathrm{f}$ = frequência. Os nomes foram suprimidos para preservar a identidade dos sujeitos da pesquisa. 
O único espaço que não exige taxa de inscrição ou de frequência é o

Tabela 4 - Atividades realizadas pelos desinteressados por grupos de convivência para idosos.

\begin{tabular}{l|l|c}
\hline \multicolumn{1}{c|}{ Atividade } & \multicolumn{1}{c}{ Exemplo } & $\mathbf{f}$ \\
\hline Interações sociais & Encontra amigos, faz amizades, conversar & 6 \\
\hline Atividades organizacionais & $\begin{array}{l}\text { Membro da diretoria, recebe visitantes, arrecada fundos, faz } \\
\text { doações e visitas, ajuda na parte elétrica }\end{array}$ & 5 \\
\hline Práticas diversas & $\begin{array}{l}\text { Coral, bordado, crochê, Pilates, oração, dança, excursão, } \\
\text { artesanato }\end{array}$ & 4 \\
\hline Festas/comemorações & Festas, aniversários, festa junina & 2 \\
\hline
\end{tabular}

Nota. $f$ = frequência.

Quanto à natureza da motivação para realizar essas atividades, 4 pessoas mencionaram a vontade própria, 2 citaram aspectos interpessoais do ambiente (por exemplo, "Você se apaixona por cada idosa, pelo carinho que cada uma precisa receber" e "Tenho respeito grande pelos sócios, aprendo muito"), 2 referiram incentivo familiar, 2 pessoas relataram outras motivações (recebe correspondência convidando; motiva-se pelas graças alcançadas) e 1 não respondeu ao perguntado.

\section{Discussão}

Primeiramente, cabe apontar as semelhanças nas atividades citadas pelos participantes e pelos egressos. Tal resultado não surpreende, visto que os egressos majoritariamente provêm dos GC dos quais originam os idosos participantes. Assim, exercícios, passeios e festas perpassam as respostas dos participantes e dos egressos. No entanto, o incentivo para o envolvimento no GC difere, com os participantes divididos entre a própria força de vontade e o incentivo de familiares, ao passo que os egressos receberam incentivo dos orientadores das atividades dos GC, bem como de pessoas próximas como familiares, amigos e vizinhos, enquanto o incentivo para o engajamento nas atividades ofertadas pelos GC, tanto os participantes como os egressos, referiram os professores como os maiores incentivadores. 
Uma explicação plausível para a diferença na natureza do incentivo ao envolvimento em GC entre os participantes e os egressos é justamente o status que assim os identifica: como atuais participantes e como egressos no momento da realização da presente pesquisa. Como fora detectado na primeira etapa da pesquisa, os egressos alegam que sua saída também foi motivada por peculiaridades da programação do GC ou mudança de seu orientador. Portanto, parece coerente que os egressos afirmem que o incentivo à frequência ao GC estava no orientador. Ao mesmo passo, os participantes, ao dividirem-se entre a motivação interna, de sua própria vontade, e a motivação externa, oriunda de familiares especificamente, demonstram vínculo forte ao GC, bem como uma relativa dependência na avaliação que os familiares realizam sobre eles. A família é o primeiro contexto de interação a perceber os ganhos usufruídos pelo idoso por seu envolvimento em GC. Assim, faz sentido encontrar nela pessoas que fomentem o engajamento do idoso nesses grupos.

É relevante para o presente estudo notar, nos desinteressados, a pequena menção a atividades físicas (Pilates e dançar). Trata-se de uma das grandes diferenças entre os desinteressados e os demais idosos do estudo (participantes e egressos). Poder-se-ia afirmar que, portanto, uma das grandes vantagens do envolvimento com GC está na prática de atividades físicas e/ou exercícios (GÁSPARI; SCHWARTZ, 2005; FENALTI; SCHWARTZ, 2003; GOMES; PINTO, 2007; PENNA; ESPÍRITO SANTO, 2006) que busquem prevenir ou mesmo, em certa medida, reabilitar. Esses grupos organizados promovem atividades e práticas que sirvam não apenas ao lazer, mas à saúde física, psicológica e social de seus integrantes. Dessa forma, caberia afirmar que os desinteressados podem se prejudicar pela não participação em GC, especialmente nesse aspecto das práticas corporais. Os resultados do presente estudo demonstraram essa escassez de atividades mais físico-motoras.

Outra diferença entre os desinteressados e os demais grupos de análise é a frequência de respostas sobre interações sociais. Os participantes e os egressos citaram menos as interações sociais como atividades desenvolvidas nos GC. Isso, muito provavelmente, está relacionado ao fato de que, na verdade, interações sociais não são atividades, mas estão presentes nelas sempre. O GC, por natureza, promove interações sociais. Outrossim, estas foram consideradas atividades em respeito às respostas fornecidas pelos sujeitos da pesquisa.

Estando ou não, os desinteressados por GC carentes de atividades e/ou exercícios físicos, esses idosos se diferenciam dos demais por outros aspectos não menos interessantes. Trata-se da quantidade de contextos nos quais eles se inserem na busca por interações sociais e por divertimento, descanso, desenvolvimento pessoal e social, enfim, por lazer. São grupos formados por algum 
objetivo específico (por exemplo, rezar), clubes, associações, aulas de Pilates, museus, creches, instituições de longa permanência para idosos (ILPI), bares e restaurantes, locais que oferecem cursos de artes manuais, etc.

Portanto, como sinalizado na primeira etapa da pesquisa e conforme demonstrado na presente segunda etapa, os desinteressados, ao contrário do que se poderia esperar, têm o tempo livre bastante ocupado por atividades e interações sociais que ocorrem em distintos espaços da cidade. Esse resultado também serve para argumentar a favor do desserviço em idealizar os GC como espaços privilegiados para a criação de vínculos sociais e envolvimento em atividades com sentido para a pessoa.

Uma das teorias que bem trata da importância dos contextos de interações para o desenvolvimento humano, do nascimento à velhice, é a de Bronfenbrenner (2011). Segundo o autor, os aspectos inatos da pessoa interagem com as forças ambientais para modelar o desenvolvimento. $\mathrm{O}$ ambiente natural influencia sobremaneira o desenvolvimento, seja para inibi-lo ou para promovê-lo. O ambiente envolve sistemas ambientais que interagem entre si e com o indivíduo, influenciando-se mutuamente. Há os microssistemas, mesossistemas, exossistemas e macrossistema. Os microssistemas são aqueles contextos nos quais o indivíduo interage face a face com pessoas significativas para sua vida, como a família nuclear, o professor e colegas da sala de aula, a casa dos avós, a creche, o local de trabalho; são espaços de interações contínuas e recorrentes, possibilitando relacionamentos sociais pelos processos proximais. A esses processos, Bronfenbrenner creditou grande importância, dado que eles requerem o envolvimento em uma atividade contínua com pessoas, símbolos ou objetos que motivem o sujeito a explorá-los e que apresentem certa complexidade. São esses processos proximais que podem gerar resultados saudáveis ou disfuncionais ao desenvolvimento.

Sendo assim, os idosos desinteressados em GC, de um lado, deixam de usufruir da programação ampla e completa destes grupos, especialmente das práticas mais corporais e de movimento, bem como da possibilidade de desenvolver relacionamentos sociais mais próximos em razão da regularidade dos encontros do GC. De outro lado, no entanto, os desinteressados da presente pesquisa participam ativamente de contextos diferenciados, neles encontrando atividades que suscitam motivação e comportamentos exploratórios, assim como o surgimento e a manutenção de relacionamentos sociais advindos dos processos proximais que contemplam as ações interessantes. Sem dúvida, são diversos os espaços, possibilitando a saída do idoso da casa, seu envolvimento com instituições públicas, privadas e filantrópicas, com atividades de lazer e de ocupação do tempo livre. 
O presente estudo apresenta os resultados da segunda etapa da pesquisa comparativa entre idosos participantes de GC, idosos egressos de GC, e idosos desinteressados por esses grupos. O principal resultado encontrado nesta etapa mostra não somente a restrição dos desinteressados a práticas ditas mais corporais, como atividades físicas, exercícios e dança, mas também a amplitude de contextos dos quais esses idosos desinteressados usufruem.

Evitando-se, como alerta a literatura, a idealizar os GC como a melhor oferta de lazer para idosos, o que se pode concluir é que, ao mesmo tempo em que os GC oferecem uma programação mais estruturada e ampla, com inclusão de atividades físicas, ele restringe a quantidade de contextos de interação ao qual o idoso pode ser exposto. Os idosos desinteressados estão participando de contextos variados ao longo da cidade, com a possibilidade de exploração de atividades de seu interesse e, portanto, intrinsecamente motivadas, bem como expostos a mais processos proximais e seu potencial para desenvolvimento saudável, especialmente se buscados com a intenção de lazer (por descanso, divertimento ou desenvolvimento pessoal ou social).

Pode-se apontar como uma das limitações do estudo o fato de que não foram solicitadas informações sobre o cônjuge ou companheiro, por exemplo, se ele participa de GC, se é egresso, ou mesmo um desinteressado. Como se pode observar, tanto para participantes como para egressos é/foi importante o incentivo de familiares para o ingresso no GC e adesão ao programa. Outra limitação é o tamanho da amostra. Este tamanho não possibilita comparações de natureza estatística com uma visão mais voltada a traçar generalizações. Outrossim, não era objetivo do presente trabalho, mas se está alertando, portanto, para serem evitadas tais generalizações.

Generalidades, ainda assim, são possíveis no sentido de que a oferta de atividades de lazer para idosos mediante grupos de convivência deve levar em consideração a importância da diversidade de contextos de interação que não apenas ofereçam atividades que demandem comportamentos exploratórios e motivação intrínseca, mas também interações sociais que possibilitem processos proximais e o surgimento de relacionamentos saudáveis. Idosos buscam novos vínculos sociais, e os GC vêm a facilitar essa busca.

Outra questão que necessita de atenção é o fato de que idosos que não participam de GC podem estar sendo privados da oferta de atividades físicas que colaborem mais diretamente para sua saúde física, seja de modo interventivo, seja preventivamente. Campanhas direcionadas ao público idoso podem 
fomentar, por exemplo, a prática da caminhada regular em espaços públicos e diferenciados como parques e praças.

O vínculo com o professor ou orientador das atividades do GC também parece ser relevante, visto que foi muito apontado como o fator incentivador para o cumprimento das práticas propostas no grupo. Os egressos, a propósito, referiram muito a mudança do professor como elemento desencadeador da saída do GC. Sobre isso, cabe mencionar que os profissionais que trabalham com idosos precisam preparar o GC com semanas de antecedência com relação à troca de professor/orientador. A experiência prática profissional dos autores da presente pesquisa permitiu constatar o desagrado quanto às trocas de orientadores, tanto por questões de esquecimento como pela falta de um planejamento prévio sobre essa alteração. Esta questão é especialmente relevante quando os GC contam com o trabalho de estagiários que, muito usualmente, mudam a cada semestre ou ano.

Futuros trabalhos devem não apenas buscar maior amostra, mas, também, incluir outros elementos de análise como o envolvimento do cônjuge ou companheiro(a), a oferta de GC no bairro do idoso, a situação dos equipamentos de lazer na região da cidade, da mesma forma que dados sobre a programação dos GC coletados com seus coordenadores. Essas inserções possibilitariam uma visão mais completa das diferenças entre participantes, egressos e desinteressados.

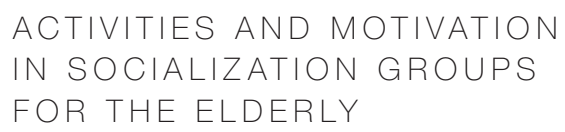

abstract

This study compared participants, former participants, and non-participants regarding socialization groups (SGs) for the elderly. Data describe activities experienced by participants and former participants in the SGs, as well as activities developed elsewhere by non-participants. Motivation for the activities is also analyzed. It is a descriptive, comparative, quali-quatitative study that tries to bring contributions to the literature on SG for the elderly, as well as to professionals that work with this population. SGs offer a more structured and broader schedule with physical activities, but with fewer contexts for social interactions. Non-participants engage on varied contexts throughout the city of Belo Horizonte, Brazil, 
with more opportunities to explore their personal interests and, therefore, more intrinsic motivation. Non-participants also seem to be exposed to more proximal processes and their potential to a healthier development, especially whether experienced as leisure (rest, fun, or social/personal development).

keywords

Elderly. Leisure Activities. Motivation. Group.

Nota: Este trabalho apresenta o segundo conjunto inédito de dados da Dissertação de Mestrado defendida pela primeira autora, sob orientação da segunda, no Programa de Pós-Graduação Interdisciplinar em Estudos do Lazer, Universidade Federal de Minas Gerais. Apoio: CAPES; PPG/ Lazer-UFMG. Esta pesquisa foi aprovada pelo Comitê de Ética em Pesquisa da UFMG no parecer ETIC190-11.

Agradecimentos: D. C. Silveira, G. A. de Moura, G. M. Schwartz, L. F. M.-Diniz, J. Doll e M. G. A. Tirado.

referências

ALVES JÚNIOR, Edmundo de Drummond. Lazer, idosos e aposentados: o projeto Prev-quedas. In: ALVES JÚNIOR, Edmundo de Drummond; MELO, Victor Andrade de; BRÊTAS, Angela (Org.). Lazer \& cidade: reflexões sobre o Rio de Janeiro. Rio de Janeiro: Shape, 2008. p. 149-217.

BARDIN, Lawrence. Análise de conteúdo. 4. ed. Lisboa: Edições 70, 2009.

BRONFENBRENNER, Urie. Bioecologia do desenvolvimento humano: tornando os seres humanos mais humanos. Porto Alegre: Artmed, 2011.

CASTRO, Odair Perugini de. O processo grupal, a subjetividade e a ressignificação da velhice. In: (Org.). Velhice, que idade é esta? Uma construção psicossocial do envelhecimento. Porto Alegre: Síntese, 1998. p. 35-55.

Sobre a vida: envelhecer no tempo e no espaço. In: (Org.). Envelhecer: um encontro inesperado? Realidades e perspectivas na trajetória do envelhecente. Sapucaia do Sul: Notadez, 2001. p. 21-42.

Vivendo em seu corpo: uma questão de consciência e de criatividade. In: (Org.). Envelhecer: revisitando o corpo. Sapucaia do Sul: Notadez, 2004. p. 13-30.

DEBERT, Guita Grin. A reinvenção da velhice: socialização e processos de reprivatização do envelhecimento. São Paulo: EDUSP, 1999.

DIAS, Aline Oliveira; SOUZA, Luciana Karine de. Entre textos e contextos: relações sociais, motivação e lazer na velhice. Licere, Belo Horizonte, v. 14, n. 4, p. 1-42, dez. 2011.

DUMAZEDIER, Joffre. Lazer e cultura popular. Tradução de Maria de Lourdes Santos Machado. São Paulo: Perspectiva, 1976.

FENALTI, Rita de Cássia de Souza; SCHWARTZ, Gisele Maria. Universidade aberta à terceira idade e a perspectiva de ressignificação do lazer. Revista Paulista de Educação Física, São Paulo, v. 17, n. 2, p. 131-141, jul./dez. 2003. 
FERNANDES, Sabrina et al. Motivos de adesão e de permanência ao Programa da Universidade Aberta à Maturidade do CEFID/UDESC. Estudos Interdisciplinares sobre o Envelhecimento, Porto Alegre, v. 16, n. 1, p. 97-110, jun. 2011.

FERRARI, Maria Auxiliadora Cursino. Lazer e ocupação do tempo livre na terceira idade. In: PAPALÉO NETTO, Matheus. Gerontologia: a velhice e o envelhecimento em visão globalizada. São Paulo: Atheneu, 2002. p. 98-105.

GÁSPARI, Jossett Campagna de; SCHWARTZ, Gisele Maria. O idoso e a ressignificação emocional do lazer. Psicologia: Teoria e Pesquisa, Brasília, v. 21, n. 1, p. 69-76, jan./abr. 2005.

GOMES, Christianne Luce; PINTO, Gabriela Baranowski. Pesquisando o lazer de um grupo de idosos no Brasil. Lecturas: Educación física y deportes, Buenos Aires, año 11, n. 106, marzo 2007. Disponível em: < http://www.efdeportes.com/efd106/ pesquisando-o-lazer-de-um-grupo-de-idosos-no-brasil.htm> Acesso em: 6 jun. 2014.

MARCELLINO, Nelson Carvalho. Algumas aproximações entre lazer e sociedade. Animador Sociocultural: Revista Iberoamericana, Rio de Janeiro, v. 1, n. 2, p. 1-20, maio/set. 2007.

MELO, Victor Andrade de. Programas de lazer para idosos no Brasil: sugestões com base em um panorama. In: (Org.). Lazer e minorias sociais. São Paulo: IBRASA, 2003. p. $57-71$

OLIVEIRA, Maria da Guia de; CABRAL, Benedita Edina. O lazer nos grupos de convivência para idosos: prática renovada de sociabilidade. In: ENCONTRO LATINO AMERICANO DE INICIAÇÃO CIENTÍFICA, 7., E ENCONTRO AMERICANO DE PÓS-GRADUAÇÃO, 4., 2004, São José dos Campos. Anais... São José dos Campos: Universidade do Vale do Paraíba, 2004, p. 1632-1638. Disponivel em: < http://www.inicepg.univap.br/cd/ INIC_2004/trabalhos/epg/pdf/EPG7-7certo.pdf> Acesso em: 6 jun. 2014.

PENNA, Fabíola Braz; ESPÍRITO SANTO, Fátima Helena do. O movimento das emoções na vida dos idosos: um estudo com um grupo da terceira idade. Revista Eletrônica de Enfermagem, Goiânia, v. 8, n. 1, p. 17-24, 2006.

PEREIRA, Larissa Almeida; PEREIRA, Alexandre Vinícius da Silva; MORELLI, Graziele A. S. A importância do lazer da terceira idade: um estudo de caso em Ribeirão Preto. Lecturas: Educación física y deportes, Buenos Aires, año 11, n. 98, jul. 2006. Disponível em: <http://www.efdeportes.com/efd98/tidade.htm>. Acesso em: 6 jun. 2014.

REZENDE, Ronaldo de. Afeto, velhice e lazer. Licere, Belo Horizonte, v. 11, n. 3, p. 1-21, dez. 2008.

SILVEIRA, Daniele Cristina et al. Produção científica nacional em lazer e envelhecimento: resultados preliminares. Belo Horizonte, 2014. Trabalho não publicado. 10 p.

SOUZA, Luciana Karine de. Velho amigo, amigo velho: amizade na velhice. In: CASTRO, Odair Perugini de (Org.). Envelhecer: revisitando o corpo. Sapucaia do Sul: Notadez, 2004. p. 69-86.

- Uma nova chance: o idoso na universidade. In: CASTRO, Odair Perugini de (Org.). Envelhecer: um encontro inesperado? Realidades e perspectivas na trajetória do envelhecente. Sapucaia do Sul: Notadez, 2001. p. 93-120.

SOUZA, Luciana Karine de; GARCIA, Agnaldo. Amizade em idosos: um panorama da produção científica recente em periódicos estrangeiros. Estudos Interdisciplinares sobre o Envelhecimento, Porto Alegre, v. 13, n. 2, p. 173-190, 2008. 
